\title{
Landscape Design Methodology of Sustainable Brownfield Regeneration
}

\author{
Yan CUI \& Wenbo FANG \\ The School of Architecture and Urban Planning, Shandong Jianzhu University, Jinan, China
}

\begin{abstract}
Industrial wasteland is a special landscape type. It is negatively influenced by severe human disturbance, which has higher heterogeneous characteristic and weaker stability, and in which various natural process including water and biological ones may be influenced. Many environmental problems occur, such as landscape fragmentation, pollution diffusion, water chaos, habitat degradation and so on. Many engineering and biological method can be used to solve these problems, including toxicity and pollution treatment, soil amends, vegetation restoration and physical repair. Accompanying with ecological restoration, landscape architecture can help regenerate and strengthen aesthetic value of industrial wasteland and will be beneficial to the health of regional eco-system, local economic development, the environment and local peoples. This thesis firstly analysis the landscape ecological characteristic and environmental effects of industrial wasteland, then summarizes various means of restoration and reconstruction basing on engineering and biological solution, evaluates different approach of utilization, and introduces some cases, it finally puts forward principles for the sustainable landscape design of industrial wasteland, including resource reuse, natural process and succession, alternative design and human place.
\end{abstract}

KEYWORD: Brownfield; Ecological Restoration; Sustainable Utilization; Landscape Design Methodology; Regeneration

\section{INTRODUCTION}

The Friction between human and land is a core problem of the sustainable development. The limited land resources and more population stop the development of society, economy and ecological environment. Post industry has come; traditional industries of developed countries go downhill, so a large industrial wastelands were left in the city. Wasteland is an area which it used to be industrial produce but not be used now, such as mining wasteland, industrial factories, platform of train, dock and so on. The industrial wasteland (Brownfield) waste great land resources and bring many ecological environmental problems. So it has a wider significance to restore and rebuild ecology of industrial wasteland and recover the value by landscape design.

\section{INDUSTRIAL WASTELAND}

\subsection{Landscape Ecological Characteristic}

Industrial wasteland is a special landscape type which people strongly affect. It shows different landscape between before and after using it. It is in a balance between life and environment before people use it [1], but the balance is broken when people used it. So its characteristic is on the following:

- The balance is broken.

- Ecosystem is affected.

\subsection{Environmental Effects of Industrial Wasteland}

\subsubsection{Pollution and Diffusion}

Many industrial activities (such as mining) pollute the surrounding environment. Some factories exhaust a lot of poisonous air and water, for example chemical plant, mining and so on. All of them are direct exhausted into the environment. It causes the quality of underground water and soil decline.

\subsubsection{Water System is Broken}

The industrial activities break the planting, the water is not maintained and the process of seepage is broken. Some activity (mining) can change the direction of underground water. [2] 


\subsubsection{The Habitat is Broken}

The biodiversity lower, the ecosystem is not a whole system; the planting which is in the first step of food chain is broken. These all affect the quantity and quality of internal species.

\section{ECOLOGICAL RESTORATION AND REBUILDING}

Ecological Society of America gives a definition for ecological restoration. It is recovering the ecosystem which people destroyed to indigenous ecosystem contains biodiversity and dynamic equilibrium. The essence is that restoring or rebuilding the area which people destroyed to an ecosystem which is friendly with the surrounding environment.

\subsection{Pollution Abatement and Soil Improve}

The pollution in industrial wasteland is a problem which must be solved; landscape architects like to try a natural method to deal with. But this method just is used in some places which are polluted not too much. For example, the gas park in Seattle, architect Richard Haag did not move out all contaminative soil. He used some humus to improve soil and cultivated some microorganism to eat the pollutant.

\subsection{Revegetation}

The vegetation in industrial wasteland is often changed beyond recognition. The whole ecosystem is broken. The short term objective of revegetation is water loss and soil erosion control [3]. The ecosystem recovery can be achieved by natural process, namely ecological succession. It will take long time. The Peak District national park in South Yorkshire, UK uses ecological succession to recover the vegetation and gets a good result.

\section{CASE STUDY}

\subsection{Bürgpark Hafeninsel}

Bürgpark Hafeninsel (Harbour Island Park) is applied ecological idea to reuse scrap materials. The site for this park was the old coaling docks on the River Saar. The island was covered with rubble and the docks lay ruinous. On the southern bank facing the island is the autobahn, which effectively has made that stretch of the river a straight concrete channel.

Latz disagreed that natural design should be made only by the forms of previously Arcadian. On the contrary, he turned his attention to the natural values of daily lives, and according to him, nature did not only change the leanness and desolation of a piece of land, but also change people's daily lives.

Latz used gravel in the ruins to build square grid in park as the framework of park.

The vestige of original wharf was retained. Industrial ruins, such as construction, warehouse, elevated railroad, etc., were utilized well by procession. Ecology fact was considered to build this park, many construction materials were gravel and rubble made by war and became an indivisibility part of the park. They synchronized with various kinds of plants. The surface water of park were collected and utilized after a series of purify treatment. The new building was built using red brick. The red brick was contrasted with the old debris. It is easy to recognize which means it has strong identity. Visitors can see the different spots belong past and now, the landscape of pure garden and art construction are completely integrated.

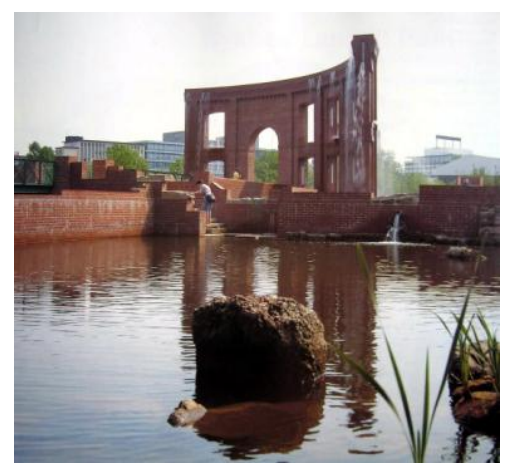

Figure1. The water tower where surface water drainage from the site is collected and cascaded in order to oxygenate it.[4]

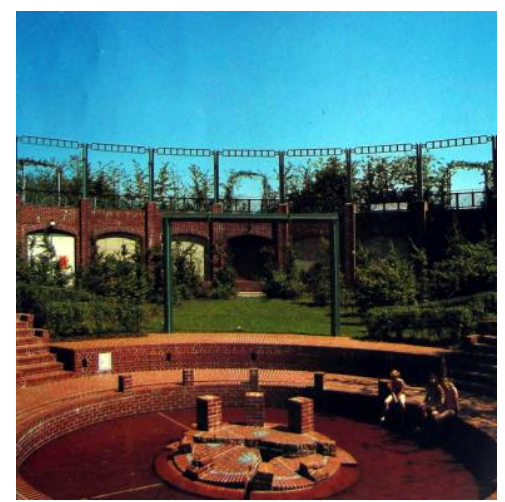

Figure2. The brick lined pool and islet in the Garden of Rest[5]

\subsection{Landschaftspark Duisburg-Nord}

Landschaftspark is a public park located in Duisburg Nord, Germany. It was designed in 1991 by Peter Latz, with the intention that it work to heal and understand the industrial past, rather than trying to reject it. The park closely associates itself with the past use of the site: a coal and steel production plant

The park is divided into different areas, whose borders were carefully developed by looking at existing conditions (such as how the site had been divided by existing roads and railways, what types of 
plants had begun to grow in each area, etc.) This piecemeal pattern was then woven together by a series of walkways and waterways, which were placed according to the old railway and sewer systems. While each piece retains its character, it also creates a dialogue with the site surrounding it. Within the main complex, Latz emphasized specific programmatic elements: the concrete bunkers create a space for a series of intimate gardens, old gas tanks have become pools for scuba divers, concrete walls are used by rock climbers, and one of the most central places of the factory, the middle of the former steel mill, has been made into piazza. Each of these spaces uses elements to allow for a specific reading of time.

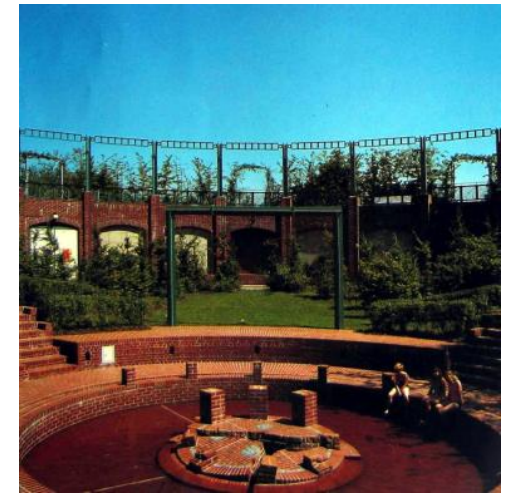

Figure3. The Piazza Metallica pays physical homage to the history of the site as a steel refinery[5]

\section{PRINCIPLES FOR THE SUSTAINABLE LANDSCAPE DESIGN OF INDUSTRIAL WASTELAND}

\subsection{Resource Reuse}

Various essential factors in industrial wasteland are reused by design and joined into the circulation of ecosystem, then created to new landscape. It can produce new value.

\subsection{Natural Process and Succession}

Recover natural ecology should be considered firstly for sustainable development of industrial wasteland. Using natural process and ecological succession are the most important method. Recovering the vegetation group and succession, improving soil, restoring natural watercourse can improve the stability of natural ecosystem.

\subsection{Diversity}

According to various possibilities in the future, it is necessary to choose diversity design to satisfy various functions and demands. To meet diversity landscape demands, the sustainable utilize of industrial wasteland should choose different method in terms of different landscape [6][7].

\subsection{Alternative Design and Human Place}

Landscape is not only visual arts but also a people used site. It should be emphasized on the importance which people participated. Different site environments can cause different feels, such as surprise, happy, silence and so on [8][9].

\section{CONCLUSION}

The type of industrial wasteland is diversity; it should be chosen suitable method by practical considerations. The cooperation between ecology and engineering can deal with the degenerative wasteland landscape. It can achieve the objective of reuse by landscape architecture, and balance the lack of resources, prevent degeneration of environment [10].

Industrial wasteland ecological restoration and sustainable landscape design refer to ecology, engineering, aesthetics, economy, social and so on. It is a strong valuable of research.

\section{ACKNOWLEDGEMENT}

This work was financially supported by Shandong Provincial Soft Science Research Program, China (2014RKB01306), Shandong Provincial Key Issues of Art Science (2014081), Jinan Science and Technology Development Plan (201409062), and Shandong Provincial Natural Science Foundation, China (2015ZRB019KR) .

\section{REFERENCES}

[1] Long H L. 1997. A Study on the theories and practices of landscape ecological reconstruction of mined-land. Process in Geography.

[2] Gregory K J and Walling D E. 1979. Man and Environmental process. Studies in Physical Geography. England: Dawson Westview Press.

[3] Anthony Bradshaw. 1997. Restoration of mined lands-using natural processes. Ecological Engineering.

[4] http://www.landscapecn.com

[5] Robert Holden 1996. International Landscape Design.

[6] Mark Johnson. 1993. Ecology and the urban aesthetic. Landscape Architecture: Ecological Design and Planning. New York: John Wiley \& Sons.

[7] James Corner. 1993. Ecology and landscape as agents of creativity. Landscape Architecture: Ecological Design and Planning. New York: John Wiley \& Sons.

[8] Brown. B. 2001 Reconstructing the Ruhrgebiet. Landscape Architecture.

[9] Yu K J. 2001. The culture Being ignored and the Beauty of Weeds-The regenerative Design of An Industrial Site, The Zhongshan Shipyard Park. New Architecture.

[10] J. Cairns Jr, 1999. Balancing ecological destruction and restoration-the only hope for sustainable use of the planet, Aquatic Ecosystem Health and Management. 